drugs. If the co-operation, therefore, between physician and surgeon is indispensable to the patient's welfare, it has become equally indispensable to the preparation of a modern manual.

These two volumes comprise a collection of essays contributed by experts in their particular subject. It was not designed as a textbook; yet.it has become if not a textbook in name, certainly a work of reference in fact. A vast deal of ground has been covered with remarkably little overlap considering the number of individual contributors.

The first volume is concerned chiefly with the general aspects of the subject, such as epidemiology, the clinical and laboratory diagnosis of the disease, morbid anatomy, radiology, administration and rehabilitation. The minimal lesion with its special problems, fluorography, B.C.G. inoculation, psychology and tuberculosis in industry are all discussed. The second volume deals with the disease more precisely by systems and contains accounts of the surgical methods employed in treatment.

Considering the entire work it can be said that the main editorial difficulty of blending so large a number of separate contributions into a composite whole has been overcome. The result is a manual that is authoritative and complete, and one which will enhance the prestige of British medical practice.

\section{A SHORT PRACTICE OF SURGERY}

ByHamilton Bailey, F.R.C.S., F.A.C.S., F.I.C.S., F.R.S.E., and R. J. McNeILl Love, M.S., F.R.C.S., F.A.C.S., F.I.C.S. 9th Edition. Pp. viii + I,254, with 1,234 illustrations. London: H. K. Lewis \& Co., Ltd. 1952.

This excellent book is now presented in its ninth edition. The authors regret that owing to surgical advances they have had to enlarge it slightly. There are 206 extra pages and it is now as large as it can be if it is to be retained as a single volume work. It has been extensively revised and brought up to date. Portal hypertension has a section to itself and the peptic ulcer chapter has been enlarged. A more comprehensive account of carcinomata of the pharynx and larynx is welcomed. In the chapter on arterial disease there is a detailed account of modern methods of treatment but it is a pity that there has been no mention of arteriography in diagnosis. The illustrations, many of which have been changed, are excellent.

This book will justly continue to be one of the most popular books for medical students.

$$
\text { D.L.B.F. }
$$

\section{INTRODUCTION TO CLINICAL NEUROLOGY}

By Gordon Holmes, M.D., F.R.S. 2nd Edition. Pp. vii + r89, with 43 illustrations. Edinburgh: E. \& S. Livingstone. 1952. I2s. 6d.

This book, as the author writes in his preface, does not "describe or deal with injuries and diseases as such,' but it discusses 'the nature and the significance of the symptoms and abnormal signs which a patient with a nervous disorder may present or which may be revealed by clinical examina.'

It is a most excellent introduction to this aspect of the study of neurology. It is also more than an introduction as it is valuable and refreshing to the initiated. Whatever its title may suggest it is emphatically a book for practitioners as well as students.

To some extent it treats in cross section the facts which are listed, so to speak, longitudinally in text books of neurology, and in so doing it elucidates and compares the same or similar signs and symptoms in different diseases.

Here are some of its chapter headings: The Motor Systems, Muscle Tone and Co-ordination of Movement, Examination of the Motor System, Sensation, The Examination of Sensation, Reflexes, The Visual System, Speech and its Disorders, Agnosia and Apraxia, The Bladder and Rectum.

This somewhat random selection gives some idea of the plan. A book with this approach is refreshing and intriguing to read, especially one as thoughtful, compact and full of experience as this. There are all too few of its kind.

To the reviewer's knowledge there is certainly no book in the British literature which covers this book's territory in its particular way.

When one remembers the striking clarity of the author's bedside demonstrations it is surprising to find that the book contains a number of obscure sentences. Some are so because they are cumbersome and others because of inadequate proofreading. However, they do not seriously detract from an excellent book.

Every aspiring neurologist or medical consultant should read it, as should any student who aims at a competent grasp of the subject of neurology.

$$
\text { C.E. }
$$

\section{THE RHESUS FACTOR}

By G. Fulton Roberts, M.A., M.D. 3rd Edition.

Pp. vii +90 . London: William Heinemann. I952. 5s.

This booklet gives an excellent account of the Rhesus factor and its clinical implications. All the relevant information is clearly set out, and many case reports further illustrate the various points raised in the text. Naturally, the main appeal will be to those engaged in blood transfusion and obstetric practice, but the importance of the subject and clarity of presentation will make this booklet highly acceptable to all practitioners.

M.H.

\section{TUBERCULOSIS OF BONE AND JOINT}

By The Late G. R. Girdlestone and E. W. Somerville, M.B., F.R.C.S. 2nd Edition. Pp. xii +314 , with 182 illustrations. London: Geoffrey Cumberlege. 1952. 45s.

Published after the untimely death of Professor Girdlestone, this second edition will keep fresh the memory of a brilliant surgeon with the widest type 
of experience on the subject of tuberculosis of bone and joint. It was fortunate that $\mathrm{Mr}$. Somerville had already been brought in as a co-author, and one hopes that senior writers of other books which grace British surgical literature may follow the example and ensure a measure of continuity of their life work. The new reader must remember that Girdlestone was a doughty campaigner for the modern régime of healthy open-air treatment, and one who never let up; for this reason some of the text reads like persuasive argument, as if the fight, now happily won, were still joined.

This book has no strong competitor in Great Britain, and such is the all-round quality of the teaching of the Oxford school that only a minor point here and there can be selected for mild critical comment. For example, the authors state that a single examination of the sedimentation rate is of little value in the diagnosis of tuberculosis. This remark is hardly fair to the test, because the finding of a raised rate often sounds a note of alarm leading to further investigation and the correct diagnosis. Many cases of early involvement of the spine and shoulder joint, not to mention ankylosing spondylitis, would have been spared manipulative mauling had this very simple test been employed only once. The baneful sideeffects of prolonged and uninterrupted immobilization in recumbency are fully discussed, but it is disappointing to find no reference to the painstaking work of Nangle, a pupil of Girdlestone, on the value of balanced suspension of frames and plaster beds, both for the patients lying on them and for the convenience of the nursing staff.

Perhaps too many rather obvious radiographs are devoted to differential diagnosis; the readers of such a special subject might reasonably be expected to be familiar with the appearance of an advanced Charcot knee, of spondylolisthesis of third degree, and of adolescent coxa vara with slipping of the head of the femur in both views. Incidentally, two of the radiographs of arthrodesis of the hip joint show the femur away out in abduction of about twenty-five degrees, much in excess of the declared ideal of nought to five degrees.

The practising surgeon, looking in vain for detailed advice on his special problem, may conclude that the book could well contain more precise instruction in the same number of pages. For example, a fuller description of the treatment and maltreatment of psoas abscess, and the way to use that essential piece of equipment, the wide-bore aspirating syringe of Gauvain, might replace a couple of the longer case-histories. Perhaps this is the direction the book will take in the years to come under its new and able editor.

K.I.N.

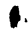

THE ETHICAL BASIS OF MEDICAL PRACTICE

By Willard L. Sperry. Pp. 185 . London: Cassell and Co. 1952. I2s. 6d.

This book fills a void in the education of the young doctor. Ethical standards should be planted in the personality of the child in its own home and nursed during school days. Often however, seeds 3 if present, do not germinate. Hence the need that $\stackrel{\varnothing}{\Omega}$ this book satisfies.

There are chapters on Medicine and the priest; $\vec{\Rightarrow}$ the specialist and the general practitioner; the $\stackrel{5}{+}$ nature of conscience, etc. It is when such subjects as euthanasia are discussed that criticism might be $\underline{\underline{D}}$ called for. Why is euthanasia a medical problem? $\frac{5}{2}$ Why is this included in the ethical basis of medical $\Phi$ practice; as distinct, for instance, from legal practice?

An action which is ethical to a Protestant may $\vec{\circ}$ be unethical to a Roman Catholic. Eating beef, $\vec{\overrightarrow{ }}$ ethical to both Protestants and Catholics is not so $\vec{\omega}$ to a Hindu. It therefore follows that it is necessary $\frac{\Omega}{8}$ for an author and also for an individual to decide $\stackrel{0}{7}$ his position and to define it if he is to write and 3 . live with sincerity and conviction. This book helps $\underset{\infty}{\mathrm{N}}$ to do this.

The duty of a doctor or a surgeon is to restore the human being to as near bodily perfection as $\dot{\sigma}$ possible and to relieve pain and anguish. Do many $\vec{\omega}$ doctors assume other functions? They may get $ᄋ$ themselves up as judges to decide who should live 을 and who should die. To be able to judge, all facts must be revealed. No human mind can ever know $\square$ all the facts. It will never be possible for a human $\mathbb{D}$ being to judge and decide whether one should live $\stackrel{\mathbb{N}}{3}$ and another should die. Therefore the question of euthanasia presents no problem to the true doctog $\underset{C}{ }$ Sometimes doctors are tempted to become prophet $\overrightarrow{0}$ They could and should give a prognosis. But 20 no man can foretell what will happen from one five minutes to the next with certainty, the death sentence should therefore never be pronounced with the conviction of the oracular.

If a man practises as a doctor in true humility his ethical problems are few. Each problem is like a $\mathbb{D}$ Savile Row tailor-made suit, i.e. it is made for a particular individual at a particular period of time; so is each ethical problem. It can only be resolved by the individual in relation to the circumstances at the time he is consulted. If on the other hand, a doctor is arrogant and takes on the function of $D$ judge, prophet and executioner the British Museum 3 is not large enough to contain all that might be written on the problems that would arise. Furthermore, these problems are not problems of medical ethics but general ethical problems.

This book discusses these matters seen through the spectacles of the Dean of Divinity at Harvard. Most helpful guidance is given in all these matters.

\section{MEDICAL HISTORY OF THE SECOND . WORLD WAR}

\section{Medicine and Pathology}

Edited by V. ZAChaRY CoPE, B.A., M.D., M.S., F.R.C.S. Pp. xxix + 565. London: H.M.S.O. I952. 5os.

The 'Medical History of the Second World $\stackrel{\Phi}{\Phi}$ War' is planned to consist of 18 volumes. Of these, the first to appear is 'Medicine and Path- 